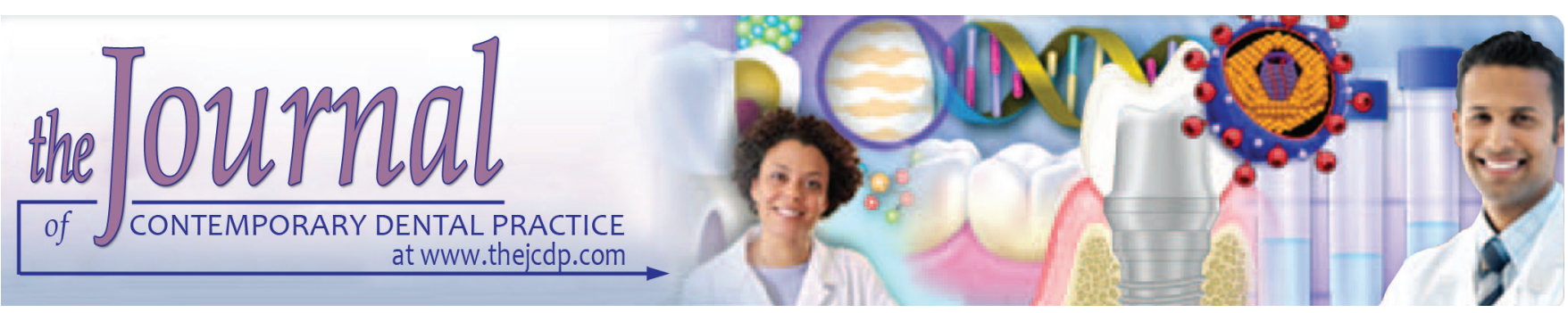

\title{
Retrospective Analysis of Different Bracket Systems used in the Treatment of Patients with Anterior Crowding: A Longitudinal Comparative Study
}

${ }^{1}$ Shipra Sepolia, ${ }^{2}$ Atul PS Kushwah, ${ }^{3}$ Amanpreet Singh Natt, ${ }^{4}$ Lipika Vashisht

${ }^{5}$ Sushil Kumar Sahoo, ${ }^{6}$ Santosh Kumar Subudhi

\begin{abstract}
Introduction: New design of brackets have been introduced in the field of orthodontics in the recent past, and one of such advancement is the self-ligating brackets. These brackets are said to have less friction, with a shorter period of treatment. Better patient acceptance and good treatment results are some of the other advantages offered by self-ligating brackets. Hence, we comparatively evaluated root resorption of anterior teeth by self-ligating and conventional preadjusted brackets in cases of severe anterior crowding in class I patients.
\end{abstract}

Materials and methods: The present study was carried out at the department of orthodontics in a dental institution and included 140 patients that presented with the chief complaint of Angle class I malocclusion with crowding of more than $6 \mathrm{~mm}$ in the anterior tooth region. Two groups were formed with 70 patients in each group. In one group self-ligating brackets were used, while in other group conventional brackets were used. Malmgren's method was sued for evaluating the root resorption score ranging from 0 to 4 . All the results were analyzed by the Statistical Package for the Social Sciences

\footnotetext{
${ }^{1}$ Department of Periodontics, Indira Gandhi Government Dental College, Jammu, Jammu and Kashmir, India

${ }^{2}$ Department of Oral and Maxillofacial Surgery, G.R. Medical College, Gwalior, Madhya Pradesh, India

${ }^{3}$ Department of Orthodontics and Dentofacial Orthopedics Dasmesh Institute of Research and Dental Sciences, Faridkot Punjab, India

${ }^{4}$ Department of Orthodontics and Dentofacial Orthopedics, Private Practice Odont Remedies, Panchkula, Haryana, India

${ }^{5,6}$ Department of Oral and Maxillofacial Surgery, Institute of Dental Sciences, Bhubaneswar, Odisha, India

Corresponding Author: Shipra Sepolia, Registrar, Department of Periodontics, Indira Gandhi Government Dental College Jammu, Jammu and Kashmir, India, Phone: +919501544877 e-mail: drshiprasepolia@yahoo.in
}

software. Chi-square test, nonpaired t-test, and paired t-test were used to evaluate the level of significance.

Results: The mean age of the patients in groups I and II was 13.92 and 13.81 years respectively. While comparing age of the patients and time duration of the treatment, no significant results were obtained. While comparing the root resorptions at various time intervals in groups I and II patients, significant results were obtained. While comparing the root resorptions in between groups I and II patients, no statistically significant results were obtained ( $p$-value $>0.05)$.

Conclusion: Statistically similar amount of resorption is seen in patients in both the groups either on self-ligating brackets or on conventional preadjusted brackets during treatment of Angle class I patients with severe anterior crowding.

Clinical significance: In treating anterior crowding patients with Angle class I patients, choice of brackets has no effect on the amount of root resorption.

Keywords: Brackets, Orthodontic treatment, Resorption.

How to cite this article: Sepolia S, Kushwah APS, Natt AS, Vashisht L, Sahoo SK, Subudhi SK. Retrospective Analysis of Different Bracket Systems used in the Treatment of Patients with Anterior Crowding: A Longitudinal Comparative Study. J Contemp Dent Pract 2016;17(8):687-691.

Source of support: Nil

Conflict of interest: None

\section{INTRODUCTION}

The search for improved efficiency in orthodontic treatment has afforded new designs of brackets. ${ }^{1}$ One such evolution occurred with the use of self-ligating brackets, which were introduced in the early 1930s but have been gaining popularity only in recent years. ${ }^{2}$ Self-ligating brackets can be divided into two main categories, active and passive, according to their mechanisms of closure. Active self-ligating brackets have a spring clip that stores 
energy to press against the arch-wire, and passive selfligating brackets usually have a slide that can be closed which does not encroach on the slot lumen, thus exerting no active force on the archwire. ${ }^{1}$ These brackets are referred to because they have less friction, a higher rate of dental movement, and shorter period of treatment. Other claimed advantages of this system are fewer appointments, improved oral hygiene, better acceptance by patients, and better treatment results. ${ }^{3}$ Although considered to have clinical advantages, the self-ligating brackets seem to present significant benefits only with regard to chair time when compared to the conventional brackets. ${ }^{1,4}$ Hence, we evaluated and compared the extent of root resorption of anterior teeth by self-ligating and conventional preadjusted brackets in cases of severe anterior crowding in class I patients.

\section{MATERIALS AND METHODS}

The present study was carried out at the department of orthodontics in a dental institution and included all the patients that presented with the chief complaint of Angle class I malocclusion with crowding of more than $6 \mathrm{~mm}$ in the anterior tooth region from June 2009 to July 2015. Ethical approval was taken from the institutional ethical committee and written consent was obtained.

Inclusion criteria for the present study included:

- Angle class I malocclusion

- Crowding of more than $6 \mathrm{~mm}$ in the anterior tooth region

- Patients in which no sign of root resorption was noticed

- Patients with all the first premolar extracted

- Patients in which complete dental records were maintained.

Exclusion criteria for the present study included:

- Patients with Angle class II malocclusion

- Patients with history of any trauma in orofacial region

- Patients with impacted anterior teeth

- Patients who underwent endodontic therapy of anterior teeth

- Patients with history of any previous orthodontic treatment

- Patients with ectopic erupted teeth or any other dental anomaly.

After fulfilling the inclusion and exclusion criteria, a total of 140 patients were enrolled in the present study. All the patients were divided into two study groups with 70 patients each. Group I included patients in which passive self-ligating brackets were used, and group II included patients in which conventional preadjustable brackets were used. Orthodontic mechanics were used, followed by slide mechanics to closed space. Transpalatal arch was used to increase the anchorage. Intraoral periapical radiographs were used to take images of periapical and root portion, and image analysis software was used for analyzing the radiographs. Measurement of length of both maxillary and mandibular incisors was done preoperatively and posttreatment on radiographs. Cementoenamel junction was used as the standard landmark for measurement of root axis. Linge and Linge ${ }^{5}$ criteria were used for the assessment of the root crown length. For correlating the radiographs of pretreatment and posttreatment phase, calculation of association factor (AF) was done.

$\mathrm{AF}=\mathrm{A} 1 / \mathrm{A} 2$

A1: Pretreatment length of crown

A2: Posttreatment length of crown

Following method was used for assessment of single tooth apical root resorption:

Apical root resorption $(\mathrm{AR})=\mathrm{K} 1-(\mathrm{K} 2 \times \mathrm{AF})$

K1: Pretreatment root length

K2: Posttreatment root length

Root resorption was expressed in percentage shortening per tooth.

Malmgren's method was sued for evaluating the root resorption score ranging from 0 to $4 .{ }^{6}$ For each group, four scores per patient that corresponded to each anterior tooth were obtained. All the results were analyzed by Statistical Package for the Social Sciences software. Chisquare test, non-paired t-test, and paired t-test were used to evaluate the level of significance; $p$-value of less than 0.05 was considered as significant.

\section{RESULTS}

Table 1 shows the $\mathrm{p}$ value for mean age at the starting and time duration of the treatment between groups I and II. The mean age of the patients in groups I and II was 13.92 and 13.81 years respectively. No significant results were obtained while comparing age of the patients and time duration of the treatment. Graph 1 shows the resorption values $(\mathrm{mm})$ of root before and after the treatment in groups I and II patients. Significant results were obtained while comparing root resorptions at various time intervals in groups I and II patients. While comparing the root resorptions in between groups I and II patients, no statistically significant results were obtained ( $p$-value $>0.05)$, as shown in Table 2. Graph 2 highlights the scores obtained according to Malmgren et al

Table 1: $p$ value for mean $\pm S D$ of age at the starting and time duration of the treatment between groups I and II

\begin{tabular}{llll}
\hline Parameter & Group I & Group II & p-value \\
\hline $\begin{array}{l}\text { Age at the } \\
\text { starting (years) }\end{array}$ & $13.92 \pm 3.01$ & $13.81 \pm 2.94$ & $0.213 \mathrm{NS}$ \\
$\begin{array}{l}\text { Time duration } \\
\text { of treatment }\end{array}$ & $20.69 \pm 3.72$ & $20.57 \pm 3.10$ & $0.312 \mathrm{NS}$ \\
\hline
\end{tabular}

NS: Nonsignificant 
Retrospective Analysis of Different Bracket Systems used in the Treatment of Patients with Anterior Crowding

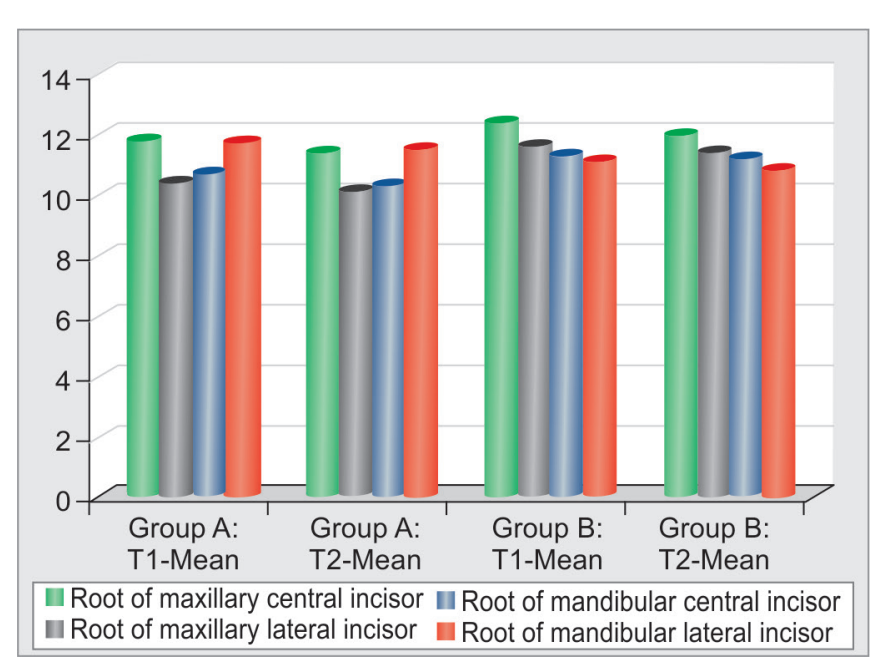

Graph 1: Assessment of resorption value $(\mathrm{mm})$ of root before and after the treatment in groups I and II patients

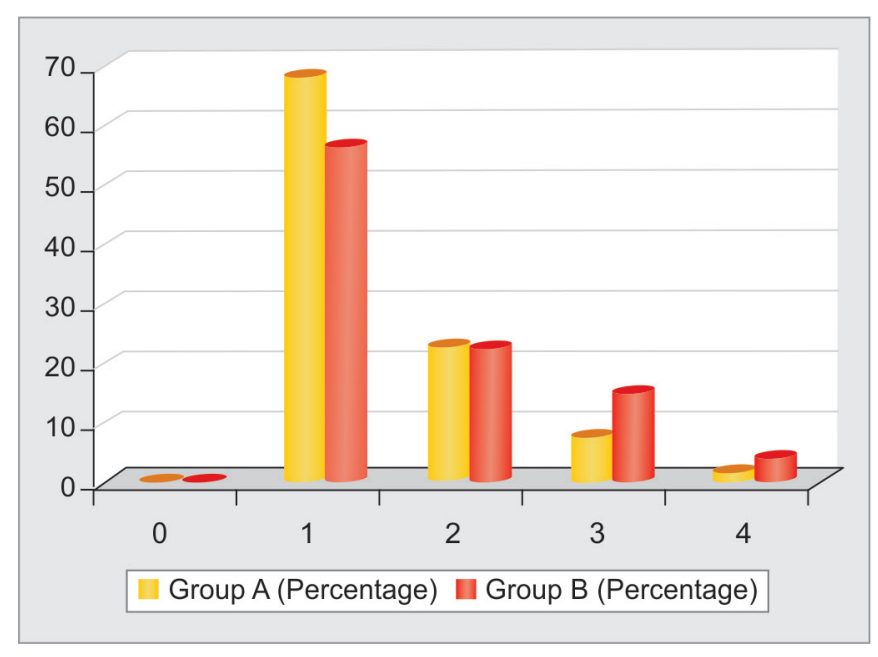

Graph 2: Scores obtained according to Malmgren et al criteria for scoring the resorption pattern

criteria for scoring the resorption pattern. Maximum number of patients in groups I and II had score of 1.

\section{DISCUSSION}

It is only a few years ago, over on years, that the self-ligating brackets were introduced in the orthodontic dentistry. However, according to Harradine, self-ligating brackets are quite old techniques (almost as old as edgewise bracket technique). ${ }^{7} \mathrm{~A}$ recent boost has been observed in the production of self-ligating appliances may be due to its certain advantages of eliminating few materials or modules associated with their use. This creates add-on advantages of reducing the chances of contamination with other components of the orthodontic treatment kit like arch-wires, elastic, etc., along with the reduction in the chances of decalcification of tooth surface by altering the plaque accumulation sites and by recuing friction in sliding mechanics. ${ }^{8-15}$ From the time since its introduction in the clinical dentistry, a lot of positive modifications
Table 2: Percent of resorption value $(\mathrm{mm})$ of root between groups I and II patients

\begin{tabular}{|c|c|c|c|}
\hline Value $(\mathrm{mm})$ & $\begin{array}{l}\text { Group I } \\
\text { (Mean } \pm S D)\end{array}$ & $\begin{array}{l}\text { Group II } \\
\text { (Mean } \pm S D)\end{array}$ & $p$-value \\
\hline $\begin{array}{l}\text { Root of maxillary } \\
\text { central incisor \% }\end{array}$ & $\begin{array}{l}2.72 \\
0.4 \pm 0.3\end{array}$ & $\begin{array}{l}4.02 \\
0.5 \pm 0.4\end{array}$ & $\begin{array}{l}0.125 \\
\text { NS }\end{array}$ \\
\hline $\begin{array}{l}\text { Root of maxillary } \\
\text { lateral incisor \% }\end{array}$ & $\begin{array}{l}2.02 \\
0.3 \pm 0.4\end{array}$ & $\begin{array}{l}2.58 \\
0.4 \pm 0.5\end{array}$ & $\begin{array}{l}0.425 \\
\text { NS }\end{array}$ \\
\hline $\begin{array}{l}\text { Root of mandibular } \\
\text { central incisor } \%\end{array}$ & $\begin{array}{l}3.58 \\
0.3 \pm 0.3\end{array}$ & $\begin{array}{l}3.38 \\
0.3 \pm 0.4\end{array}$ & $\begin{array}{l}0.512 \\
\text { NS }\end{array}$ \\
\hline $\begin{array}{l}\text { Root of mandibular } \\
\text { lateral incisor } \%\end{array}$ & $\begin{array}{l}2.64 \\
0.4 \pm 0.4\end{array}$ & $\begin{array}{l}2.79 \\
0.4 \pm 0.3\end{array}$ & $\begin{array}{l}0.325 \\
\text { NS }\end{array}$ \\
\hline
\end{tabular}

\section{S: Significant; NS: Nonsignificant}

have been done in these brackets which has simplified its usage in orthodontics by overcoming various handling problems and difficulties. However, many of these positive effects of self-ligating brackets are presumptive only. ${ }^{16,17}$ Hence, we evaluated and compared the extent of root resorption of anterior teeth by self-ligating and conventional preadjusted brackets in cases of severe anterior crowding in class I patients between self-ligating and conventional preadjusted brackets.

The mean age of the patients in groups I and II was 13.92 and 13.81 years respectively (Table 1 ). Mean resorption of 0.32 and $0.36 \mathrm{~mm}$ was seen in the present study in groups I and II respectively (Graph 1). A very close association of the results was seen when compared with the standard results of past literature, as reported by Malmgren et al. ${ }^{6}$ Even though some amount of resorption was present in nearly all the teeth, the value when considered from clinical point of view was not relevant. ${ }^{18}$ Long duration of the treatment along with nature of the forces were responsible for the resorption to occur, while a positive correlation was observed with the duration of treatment and amount of resorption seen. Long-term turnover seen in the bone in association with the movement of teeth might be responsible for the resorption of root. No statistically significant results were obtained while comparing the mean root resorption and Malmgren's score in the two study groups (Table 2, Graph 2). Similar results were observed by Chen et al, ${ }^{19}$ who also observed nonsignificant results in their study. Similar results have been also quoted by various authors in the literature. ${ }^{20,21}$ Leitea et al using incisors compared the amount of root resorption in patients who underwent starting stage of orthodontic treatment with two different sets of brackets. They noticed significant alteration in the two study groups at T1 and T2. However, nonsignificant alteration was noticed when comparison of resorption was made in between the two groups. From the results, they concluded that difference in brackets designs does not alter the treatment outcomes.22 Ribeiro et al comparatively evaluated the efficacy of two types of bracket systems while correcting crowding of mandibular teeth. They 
observed significant alterations on comparing the correction of mandibular crowding between $\mathrm{T} 1$ and $\mathrm{T} 3$ time interval. ${ }^{23}$ Gebeile-Chauty et al reviewed the literature to assess the effect of self-ligating and traditional brackets in nonextraction orthodontic treatment cases. From the results, they concluded that no reduction in pain was observed in self-ligating brackets cases. Also reduction in the clinical time was observed in patients in whom self-ligating brackets were used. ${ }^{24}$ Handem et al assessed and compared the amount of root resorption in patients undergoing orthodontic treatment with self-ligating and with conventional appliances. They evaluated 52 patients and randomly divided them into two groups: One group containing patients treated with self-ligating Damon appliances and other group containing conventional preadjusted appliances. They did not observe any significant difference in the amount of root resorption in the two groups. From the results they concluded that similar amount of resorption occurs when any one of the two types of appliances is used for patients undergoing orthodontic treatment in nonextraction cases..$^{25}$ Chen et al tested the statistical difference between the amount of root resorption occurring in patients undergoing orthodontic treatment with either conventional brackets or the self-ligating brackets. After evaluating the results, they concluded that no significant difference occurs in the degree of root resorption in cases treated with either self-ligating or conventional brackets in treating Angle class I patients with severe crowding in the anterior region. ${ }^{19}$

\section{CONCLUSION}

From the above results, we conclude that statistically similar amount of resorption occurs in patients using either self-ligating brackets or conventional brackets during treatment of Angle class I patients with severe anterior crowding. Future studies in this field are advocated to further explore this field.

\section{REFERENCES}

1. Chen SSH, Greenlee GM, Kim J, Smith CL, Huang GJ. Systematic review of self-ligating brackets. Am J Orthod Dentofacial Orthop 2010 Jun;137(6):726.e1-726.e18.

2. Stolzenberg J. The Russell attachment and its improved advantages. Int J Orthod Dent Child 1935 Sep;21(9):837-840.

3. Berger J, Byloff FK. The clinical efficiency of self-ligated brackets. J Clin Orthod 2001 May;35(5):304-308.

4. Fleming SP, Dibiase AT, Lee RT. Randomized clinical trial of orthodontic treatment efficiency with self-ligating and conventional fixed orthodontic appliances. Am J Orthod Dentofacial Orthop 2010 Jun;137(6):738-742.

5. Linge L, Linge BO. Patient characteristics and treatment variables associated with apical root resorption during orthodontic treatment. Am J Orthod Dentofacial Orthop 1991 Jan;99(1):35-43.

6. Malmgren O, Goldson L, Hill C, Orwin A, Petrini L, Lundberg M. Root resorption after orthodontic treatment of traumatized teeth. Am J Orthod 1982 Dec;82:487-491.

7. Harradine HNW. Self-ligating brackets: Where are we now? J Orthod 2003 Sep;30(3):262-273.

8. Khambay B, Millett D, McHugh S. Evaluation of methods of archwire ligation on frictional resistance. Eur J Orthod 2004 Jun;26(3):327-332.

9. Cacciafesta V, Sfondrini MF, Ricciardi A, Scribante A, Klersy C, Auricchio F. Evaluation of friction of stainless steel and esthetic self-ligating brackets in various bracketarchwire combinations. Am J Orthod Dentofacial Orthop 2003 Oct;124(4):395-402.

10. Griffiths HS, Sherriff M, Ireland AJ. Resistance to sliding with 3 types of elastomeric modules. Am J Orthod Dentofacial Orthop 2005 Jun;127(6):670-675.

11. Thomas S, Sherriff M, Birnie D. A comparative in vitro study of the frictional characteristics of two types of self-ligating brackets and two types of pre-adjusted edgewise brackets tied with elastomeric ligatures. Eur J Orthod 1998 Oct;20(5): 589-596.

12. Hain M, Dhopatkar A, Rock P. The effect of ligation method on friction in sliding mechanics. Am J Orthod Dentofacial Orthop 2003 Apr;123(4):416-422.

13. Pizzoni L, Ravnholt G, Melsen B. Frictional forces related to self-ligating brackets. Eur J Orthod 1998 Jun;20:283-291.

14. Shivapuja PK, Berger J. A comparative study of conventional ligation and self-ligation bracket systems. Am J Orthod Dentofacial Orthop 1994 Nov;106(5):472-480.

15. Sims AP, Waters NE, Birnie DJ, Pethybridge RJ. A comparison of the forces required to produce tooth movement in vitro using two self-ligating brackets and a pre-adjusted bracket employing two types of ligation. Eur J Orthod 1993 Oct;15(5):377-385.

16. Eliades, T.; Brantley, WA.; Eliades, G. Orthodontic brackets. In: Brantley, WA.; Eliades, T., editors. Orthodontic materials: Scientific and clinical aspects. Stuttgart: Thieme; 2001. p. $143-172$.

17. Blake M, Woodside DG, Pharoah MJ. A radiographic comparison of apical root resorption after orthodontic treatment with the edgewise and Speed appliances. Am J Orthod Dentofacial Orthop 1995 Jul;108(1):76-84.

18. Smale I, Artun J, Behbehani F, Doppel D, Van't Hof M, Kuijpers-Jagtman AM. Apical root resorption 6 months after initiation of fixed orthodontic appliance therapy. Am J Orthod Dentofacial Orthop 2005 Jul;128(1):57-67.

19. Chen W, Haq AAA, Zhou Y. Root resorption of self-ligating and conventional preadjusted brackets in severe anterior crowding Class I patients: a longitudinal retrospective study. BMC Oral Health 2015 Oct;15(115):1-6.

20. Scott P, Di Biase AT, Sherriff M, Cobourne M. Alignment efficiency of Damon 3 self-ligating and conventional orthodontic bracket systems: a randomized clinical trial. Am J Orthod Dentofacial Orthop 2008 Oct;134(4):470.e1-8.

21. Pandis N. External apical root resorption in patients treated with conventional and self-ligating brackets. Am J Orthod Dentofacial Orthop 2008 Nov;134(5):646-651.

22. Leitea V, Contib AC, Navarrob R, Almeidab M, OltramariNavarrob P, Almeidab R. Comparison of root resorption between self-ligating and conventional preadjusted brackets 
using cone beam computed tomography. Angle Orthod 2012 Nov;82(6):1078-1082.

23. Ribeiro DAG, deAlmeida MR, Conti AC, Navarro R, OltramariNavarro P, Almeida R, Fernandes T. Efficiency of mandibular arch alignment with self-ligating and conventional edgewise appliances: a dental cast study. Dentistry 2012 Apr; 2(3):1-5.
24. Gebeile-Chauty S. Are self-ligating brackets an advantageous alternative for non-extraction treatments? J Dentofacial Anom Orthod 2014 Jan;17(402):1-11.

25. Handem RH, Janson G, Matias M, de Freitas KMS, de Lima DV, Garib DG, de Freitas MR. External root resorption with the self-ligating Damon system - A retrospective study. Prog Orthod 2016 Dec;17(1):20. 